\title{
Pulse-Extended Excimer Laser Crystallisation of Ferroelectric Thin Films for Integration on Low Thermal Budget Substrates
}

\author{
P.P. DONOHUE ${ }^{1}$, M.A. TODD ${ }^{1}$ and Z. HUANG ${ }^{2}$ \\ ${ }^{1}$ QinetiQ Ltd, Malvern Technology Centre, St. Andrews Road, \\ Malvern, Worcestershire, WR14 3PS, UK \\ ${ }^{2}$ Department of Advanced Materials, \\ School of Industrial and Manufacturing Science, \\ Cranfield University, Bedfordshire, MK43 OAL,UK
}

\begin{abstract}
The use of pulsed laser annealing in ferroelectric device processing is of interest for integration of materials such as lead zirconate titanate (PZT) and strontium bismuth tantalate (SBT) on low thermal budget substrates. Excimer lasers provide a suitable radiation source in a short pulse-duration format with photon energies above the ferroelectric bandgap. Studies with thin film PZT have revealed that standard excimer laser annealing can preferentially heat the ferroelectric layer relative to the substrate but results in severe surface heating and poor heat distribution in this layer. A pulse-extension technique has been used to lengthen the laser pulse duration from $25 \mathrm{~ns}$ to $374 \mathrm{~ns}$, lowering the surface temperature and improving the heat distribution in the PZT but still not significantly heating the substrate. Initial experiments have shown the technique to be capable of crystallising over half a 500nm thick PZT film to perovskite although a melting effect limited the converted thickness. The thickness crystallised is however of the order of that used in FeRAM devices and modelled temperature profiles suggest that the technique provides a tractable solution for high temperature processing of ferroelectric thin films on low thermal budget substrates.
\end{abstract}

Keywords: Laser annealing, pulse-extension, ferroelectric, thin film.

\section{INTRODUCTION}

Excimer lasers are widely used for annealing of thin films of materials that require a higher crystallisation temperature than the substrates on which they sit can withstand. Examples are the crystallisation of a-Si on low thermal budget glass substrates for TFT's in liquid crystal display applications ${ }^{[1,2]}$, solar cells and IC's on flexible substrates ${ }^{[3]}$. Some work has been reported on excimer laser annealing of ferroelectric thin films, both cystallisation from an amorphous state ${ }^{[4]}$ and a two step crystallisation process involving combined furnace/laser annealing ${ }^{[5,6]}$ whereby a low temperature perovskite 


\section{P P DONOHUE et al}

phase is initiated by a relatively low temperature and long duration furnace anneal and then refined by laser annealing. This paper details a novel development of excimer laser annealing where the films are annealed from the amorphous state using pulses which have been temporally extended ${ }^{[7,8]}$. The extension of the pulse duration (fwhm), from 25ns to 374ns, alleviates two of the main problems of excimer laser annealing of ferroelectric thin films, namely high surface temperatures and poor heat distribution, by increasing the diffusion length of the heat generated during the pulse, while still retaining the benefit of not significantly heating the underlying substrate.

\section{EXPERIMENT}

Thin film PZT 30/70 with a 10\% Pb excess was deposited using the sol-gel technique ${ }^{[9,10]}$ onto platinised silicon substrates giving the structure $\operatorname{PZT}(\sim 500 \mathrm{~nm}) / \mathrm{Pt}(1000 \Sigma) / \mathrm{Ti}(100 \Sigma) / \mathrm{SiO}_{2}(0.8 \mu \mathrm{m}) / \mathrm{Si}$. Each PZT layer was fired at $400^{\circ} \mathrm{C}$ to remove organic components. The optical properties of the as-deposited PZT, used for modelling purposes, were measured using reflectometry and spectroscopic ellipsometry. Laser annealing was accomplished using a bespoke system, described in detail elsewhere ${ }^{[7,8]}$, comprising a Lambda Physik LPX210 KrF excimer laser (248nm), pulseextension optics (25ns pulse width to $374 \mathrm{~ns}$ pulse width), a Microlas beam homogeniser $(8 \mathrm{~mm} \times 8 \mathrm{~mm}$ uniform beam to $\pm 5 \%$ ) and a vacuum compatible annealing chamber with heated substrate holder. Temporal pulse shapes were measured using an ITL vacuum photodiode coupled to a Gould 4094 DSO.

The PZT thin films were assessed using X-Ray diffraction (XRD), scanning electron microscopy (SEM), energy dispersive spectroscopy (EDS) and transmission electron microscopy (TEM) techniques. Detailed crystallographic phase investigations were made using small area electron diffraction (SAED) in a Philips CM20 TEM.

\section{TEMPERATURE PROFILE MODELLING}

The temperature profiles developed in the thin film layer stacks due to laser irradiation have been predicted by solution of the heat diffusion equation with the addition of a source term for laser induced heating. When a beam homogeniser is used then away from the edge of the illuminated region the heat diffusion problem can be reduced to the unidimensional case since any temperature variation will occur only along an axis perpendicular to the sample surface. Additionally the annealing conditions and materials properties are such that heat flow by radiation, convection and conduction into the surrounding atmosphere can be neglected. The temperature $\mathrm{T}$ at distance $\mathrm{z}$ from the illuminated surface and time $\mathrm{t}$ is then given by 


$$
\frac{\partial T}{\partial t}=\frac{\alpha}{\rho c_{p}} I(z, t)+\frac{1}{\rho c_{p}} \frac{\partial}{\partial z}\left(\kappa \frac{\partial T}{\partial z}\right)
$$

where I is the laser power density, $\alpha$ is the optical absorption coefficient, $\rho$ is the density, $c_{p}$ is the specific heat capacity and $\kappa$ is the thermal conductivity. The optical constants of the PZT thin films were determined experimentally and thermal properties for each layer were those determined for bulk materials ${ }^{[11,12,13]}$, the layers considered being sufficiently thick for this to be a valid assumption ${ }^{[8]}$. Due to the complex nature of the samples equation (1) is not solvable analytically. A forward time finite difference approach, described in detail elsewhere ${ }^{[7,8,14]}$, has been used to solve for the temperature distribution. The approach adopted involved the layer structure be discritised into finite slices of thickness $50 \mathrm{~nm}$, temperatures output being the average for each slice, and time discritised into 25ps units. This numerical approach allowed temperature variation of the layer thermal properties to be taken into account and also measured pulse temporal profiles to be used.

\section{RESULTS}

\section{0nm Thick PZT Films}

Modelled temperature profiles in the PZT layer stack are shown for the case of a non-extended pulse (fwhm 25ns) in Figures 1 and 2. Figure 1 illustrates the temperatures developed in the PZT slices during and after a pulse of fluence $100 \mathrm{~mJ} / \mathrm{cm}^{2}$, assuming an ambient temperature of $300^{\circ} \mathrm{C}$. The curve labelled PZT surface is the slice adjacent to the film surface while that labelled PZT/Pt interface is the slice adjacent to the Pt. Figure 2 shows a cross section through the layer stack (the thin Ti adhesion layer has been omitted) at several times after the onset of the pulse. It can be seen from the figures that the non-extended pulse induces very high surface temperatures and large temperature gradients in the PZT - primarily due to the very short absorption length ( $20 \mathrm{~nm}$ at $248 \mathrm{~nm})$ and low thermal diffusivity $\left(\sim 5 \times 10^{-}\right.$ ${ }^{7} \mathrm{~m}^{2} / \mathrm{s}$ ) of this layer. The surface temperature of the PZT reaches a maximum of $1758^{\circ} \mathrm{C}$, with the PZT adjacent to the Pt reaching $444^{\circ} \mathrm{C}$. Interestingly the uppermost portion of the Si substrate reaches a maximum of only $324^{\circ} \mathrm{C}$, only $24^{\circ} \mathrm{C}$ above ambient, partly due to the thermal barrier action of the $\mathrm{SiO}_{2}$. 


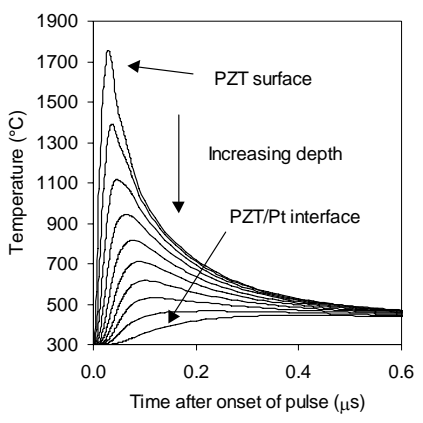

Figure 1: Modelled temperature distribution in a 500nm thick

PZT thin film due to nonextended laser pulse of fluence $100 \mathrm{~mJ} / \mathrm{cm}^{2}$

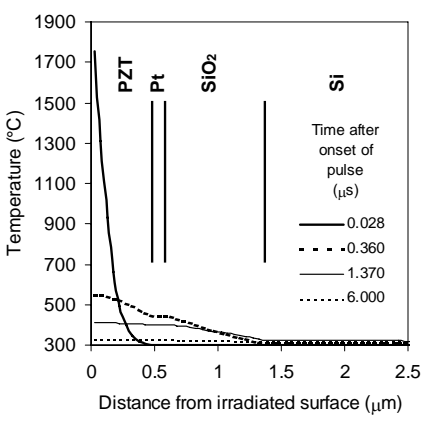

Figure 2: Modelled temperature distribution in layer stack with 500nm thick PZT thin film and non- extended laser pulse of fluence $100 \mathrm{~mJ} / \mathrm{cm}^{2}$

Figures 3 and 4 show the same plots for an extended pulse of the same fluence, $100 \mathrm{~mJ} / \mathrm{cm}^{2}$. The surface temperature is lower than for the non-extended case, maximum $805^{\circ} \mathrm{C}$, while the temperature of the PZT adjacent to the $\mathrm{Pt}$ is very similar at $438^{\circ} \mathrm{C}$ - indicating a better temperature distribution in the PZT layer due to the extended pulse increasing the diffusion length by around factor of four. The extended pulse is still sufficiently short however for the maximum temperature of the topmost Si to only reach $324^{\circ} \mathrm{C}$ - the same value as for the non-extended case.

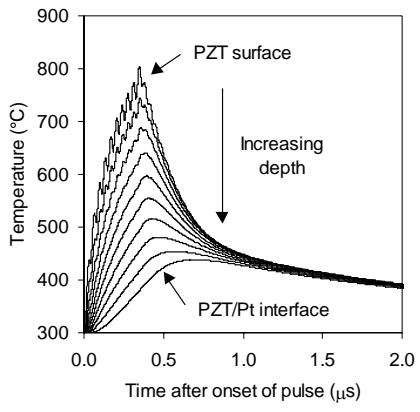

Figure 3: Modelled temperature distribution in a 300nm thick

PZT thin film due to an extended laser pulse of fluence $100 \mathrm{~mJ} / \mathrm{cm}^{2}$

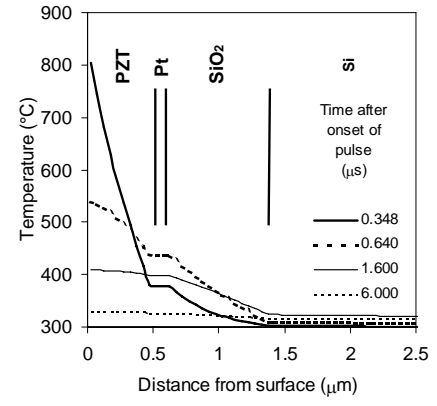

Figure 4: Modelled temperature distribution in layer stack with 500nm thick PZT thin film and extended laser pulse of fluence $100 \mathrm{~mJ} / \mathrm{cm}^{2}$

Using the modelled temperature profiles as a guide to the required fluence level PZT thin films were annealed using extended pulses in an $\mathrm{O}_{2}$ 


\section{LASER CRYSTALLISATION OF FERROELECTRIC}

atmosphere with the ambient temperature set to $300^{\circ} \mathrm{C}$. Detailed microstructural analysis has been presented previously ${ }^{[7,8]}$, but the films have, for fluence levels of $\sim 100 \mathrm{~mJ} / \mathrm{cm}^{2}$ and less, crystallised to perovskite with no surface damage. The PZT crystal structure, from the top surface down, determined by SAED was perovskite/pyrochlore/amorphous with no perovskite nucleation or growth at the PZT/Pt interface. Table 1 below gives the thickness of the perovskite, pyrochlore and amorphous regions in the PZT for various fluence levels and pulse counts. The thickest perovskite layer was $280 \mathrm{~nm}$, over half the original film thickness, and was formed by $10^{4}$ pulses at a fluence of $100 \mathrm{~mJ} / \mathrm{cm}^{2}$.

\begin{tabular}{|c|c|c|c|c|}
\hline \multicolumn{2}{|c|}{ Anneal conditions } & \multirow{2}{*}{$\begin{array}{l}\text { Perovskite } \\
\text { Region } \\
\text { Thickness } \\
\text { (nm) }\end{array}$} & \multirow{2}{*}{$\begin{array}{l}\text { Pyrochlore } \\
\text { Region } \\
\text { Thickness } \\
\text { (nm) }\end{array}$} & \multirow{2}{*}{$\begin{array}{l}\text { Amorphous } \\
\text { Region } \\
\text { Thickness } \\
\text { (nm) }\end{array}$} \\
\hline $\begin{array}{c}\text { Number } \\
\text { of } \\
\text { Pulses }\end{array}$ & $\begin{array}{l}\text { Fluence } \\
\left(\mathrm{mJ} / \mathrm{cm}^{2}\right)\end{array}$ & & & \\
\hline $10^{4}$ & 80 & 157 & 107 & 221 \\
\hline $16 \times 10^{4}$ & 80 & 154 & 100 & 231 \\
\hline $10^{4}+10^{4}$ & $80+100$ & 242 & 99 & 144 \\
\hline $10^{4}$ & 100 & 280 & 81 & 114 \\
\hline
\end{tabular}

Table 1: Crystallisation thicknesses in pulse-extended laser annealed PZT thin films.

An interesting surface-damage effect was observed when the fluence level was increased above $100 \mathrm{~mJ} / \mathrm{cm}^{2}$. Figures 5, 6 and 7 show SEM pictures of sample surfaces at fluence levels of $80 \mathrm{~mJ} / \mathrm{cm}^{2}\left(10^{4}\right.$ pulses $), 117 \mathrm{~mJ} / \mathrm{cm}^{2}\left(10^{2}\right.$ pulses) and $200 \mathrm{~mJ} / \mathrm{cm}^{2}\left(10^{3}\right.$ pulses) respectively. At $80 \mathrm{~mJ} / \mathrm{cm}^{2}$ the surface is smooth while at $117 \mathrm{~mJ} / \mathrm{cm}^{2}$ small pits are starting to appear. Increasing the fluence to $200 \mathrm{~mJ} / \mathrm{cm}^{2}$ resulted in dramatic surface disruption and what appears to be a melt pattern. It may be noted that the $117 \mathrm{~mJ} / \mathrm{cm}^{2}$ and $200 \mathrm{~mJ} / \mathrm{cm}^{2}$ annealed films had the same composition as the as-deposited films and both showed some degree of perovskite crystallisation. Figure 8 shows the modelled maximum temperatures attained at various depths in the PZT at the three fluence levels. Also indicated is the melting temperature of $\mathrm{PbO}, 886^{\circ} \mathrm{C}$, the component in the original film with the lowest melting point. The modelled temperature distributions do not take into account phase changes, such as melting, and should only be considered as a rough guide only. For a fluence of $80 \mathrm{~mJ} / \mathrm{cm}^{2}$ the whole PZT film is well below the $\mathrm{PbO}$ melting temperature. At $117 \mathrm{~mJ} / \mathrm{cm}^{2}$ however the very top of the film has reached the $\mathrm{PbO}$ melting temperature, corresponding to small scale pitting in the SEM picture, while at $200 \mathrm{~mJ} / \mathrm{cm}^{2}$ this has increased to around half the PZT thickness, corresponding to gross disruption in the annealed film. 


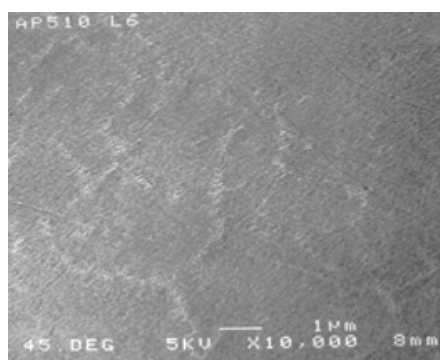

Figure 5: Surface of PZT thin film annealed with extended pulses of fluence $80 \mathrm{~mJ} / \mathrm{cm}^{2}$.

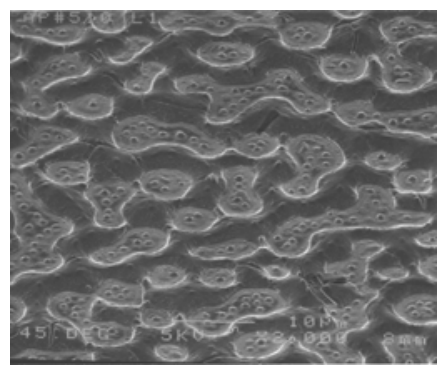

Figure 7: Surface of PZT thin film annealed with extended pulses of fluence $200 \mathrm{~mJ} / \mathrm{cm}^{2}$.

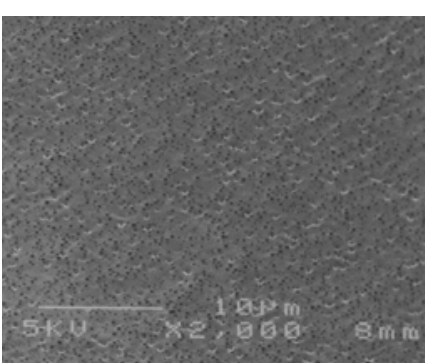

Figure 6: Surface of PZT thin film annealed with extended pulses of fluence $117 \mathrm{~mJ} / \mathrm{cm}^{2}$.

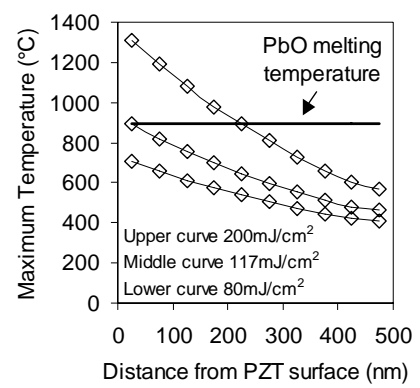

Figure 8: Maximum slice temperature versus extended pulse fluence.

\section{0nm and 300nm Thick PZT Films}

Since the pulse-extension technique is limited in the thickness of perovskite PZT that can be crystallised, due to fluence limitations identified in the previous section, thinner layers were modelled to determine the temperature distributions. Figures 9 and 10 show the temperature distribution in a 300nm thick PZT film and in the whole layer stack respectively for an extended pulse of fluence $100 \mathrm{~mJ} / \mathrm{cm}^{2}$ and an ambient temperature of $300^{\circ} \mathrm{C}$. The temperature distribution in the PZT is seen to be better than for the $500 \mathrm{~nm}$ thick film with the maximum surface and $\mathrm{PZT} / \mathrm{Pt}$ interface temperatures being $712^{\circ} \mathrm{C}$ and $468^{\circ} \mathrm{C}$ respectively, a difference of $244^{\circ} \mathrm{C}$, while the topmost part of the $\mathrm{Si}$ only reaches a maximum of $327^{\circ} \mathrm{C}$. For a $200 \mathrm{~nm}$ thick PZT film, Figures 11 and 12, the situation improves further with maximum surface and PZT/Pt interface temperatures being $643^{\circ} \mathrm{C}$ and $483^{\circ} \mathrm{C}$ respectively, a difference of only $160^{\circ} \mathrm{C}$, while the topmost $\mathrm{Si}$ only reached a temperature of $328^{\circ} \mathrm{C}$. Compared with the 500nm thick PZT films pulseextended annealing of these thinner films will benefit from lower surface temperatures and a much improved heat distribution within the PZT film, 


\section{LASER CRYSTALLISATION OF FERROELECTRIC}

without any apparent penalty in laser induced substrate heating. The portion of the PZT film close to the Pt is also getting sufficiently hot for perovskite crystallisation $^{[15]}$.

Since the PZT surface temperatures for the thinner films are distinctly lower than the $\mathrm{PbO}$ melting temperature, $253^{\circ} \mathrm{C}$ lower for the $200 \mathrm{~nm}$ thick film, there is scope for increasing the fluence and bringing the entire PZT film up to the temperature levels used in the Rapid Thermal Processor (RTP) annealing route without taking the substrate above detrimental temperatures - 450-500 ${ }^{\circ} \mathrm{C}$ for standard Al based CMOS circuitry.

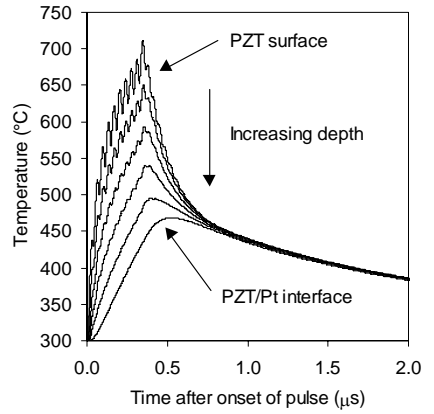

Figure 9: Modelled temperature distribution in a 300nm thick PZT thin film due to an extended laser pulse of fluence $100 \mathrm{~mJ} / \mathrm{cm}^{2}$

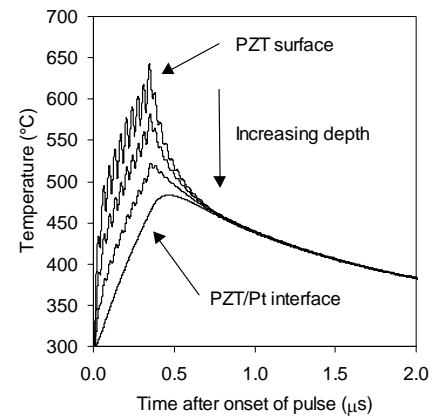

Figure 11: Modelled temperature distribution in a 200nm thick PZT thin film due to an extended laser pulse of fluence $100 \mathrm{~mJ} / \mathrm{cm}^{2}$

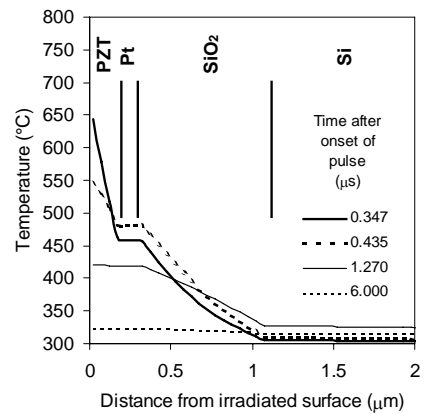

Figure 10: Modelled temperature distribution in layer stack with 300nm thick PZT thin film and extended laser pulse of fluence $100 \mathrm{~mJ} / \mathrm{cm}^{2}$

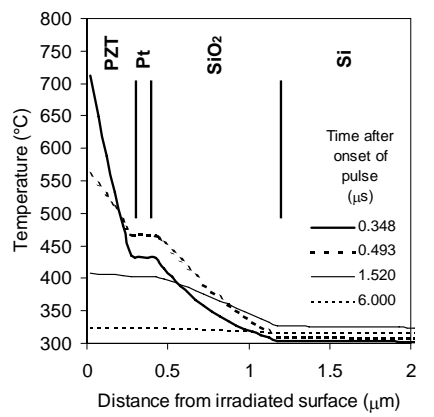

Figure 12: Modelled temperature distribution in layer stack with 200nm thick PZT thin film and extended laser pulse of fluence $100 \mathrm{~mJ} / \mathrm{cm}^{2}$

\section{DISCUSSION AND CONCLUSIONS}




\section{P P DONOHUE et al}

Low temperature deposited PZT thin films can be crystallised into the perovskite phase using pulse-extended excimer laser annealing. Additionally the temperature rise is largely confined to the ferroelectric layer making the technique suitable for applications which involve low thermal budget substrates, such as FeRAM devices - especially involving SBT films which require very high temperature processing. Compared to annealing with a standard pulse the action of the pulse extender slows down the rate of energy delivery to the PZT, giving lower surface temperatures and improved heat distribution. Use of this technique has been shown to be able to crystallise up to 280nm of an amorphous PZT film to perovskite, which is of the order of the thickness required for ferroelectric based non-volatile memory. The thickness of film that can be crystallised is however limited due to fluence restrictions believed to be due to melting of the $\mathrm{PbO}$ component in the as-deposited PZT. Modelling studies have however indicated that for thinner films, of the order of $200-300 \mathrm{~nm}$ in thickness, the technique should be capable of raising the entire PZT thin films to temperatures used in conventional annealing treatments, e.g. RTP, without detrimentally heating a low thermal budget substrate such as CMOS circuitry.

\section{ACKNOWLEDGEMENTS}

This work was funded by the UK Ministry of Defence. The authors gratefully acknowledge the contributions of their colleagues at QinetiQ, Prof. R.W. Whatmore of Cranfield University, Prof. H.N. Rutt of Southampton University and Dr. P. Rumsby of Exitech Ltd. Dr. A. Patel of BAE Systems is thanked for supplying the thin film PZT. (C) QinetiQ ltd 2002.

\section{REFERENCES}

[1] K. Sera, F. Okumura, H. Uchida, S. Itoh, S. Kaneko and K. Hotta, IEEE Trans. on Electron Devices 36(12), 2868 (1989).

[2] S.D. Brotherton, J.R. Ayres, M.J. Edwards, C.A. Fisher, C. Glaister, J.P. Gowers, D.J. McCulloch and M. Trainor, Thin Solid Films 337, 188 (1999).

[3] Semiconductor International, August 2001, p40.

[4] U. Varshney, B.D. Eischelberger and R.D. Churchill, Virtual Proceedings of 1996 NSF Design and Manufacturing Grantees Conference.

[5] Y. Zhu, J. Zhu, Y.J. Song and S.B. Desu, Appl. Phys. Lett. 73(14), 1958 (1998).

[6] Z. Zhang, J. Zhu, D. Su, J. Liu, H. Shen, Y. Wang, L. Kang, J. Zhou, S. Yang and P. Wu, Thin Solid Films 375, 172 (2000).

[7] P.P. Donohue, PhD Thesis, University of Southampton, 2000.

[8] P.P. Donohue and M.A. Todd, Intetegrated Ferroelectrics 31, 285 (2000).

[9] A Patel and J Obhi, GEC J. Res. 12, 141 (1995). 


\section{LASER CRYSTALLISATION OF FERROELECTRIC}

[10] Q. Zhang, R.W. Whatmore, M.E. Vickers and A. Patel, J. Korean Physical Society 32, S572 (1998).

[11] CRC Handbook of Chemistry and Physics, D R Lide, $76^{\text {th }}$ Ed., CRC Press, 1996

[12] Tables of Physical and Chemical Constants, G.W.C. Kaye and T.H. Laby, $15^{\text {th }}$ Ed., Longman Scientific and Technical, 1993.

[13] PZT Bulk Ceramic Thermal Properties, N.M. Shorrocks, private communication.

[14] P. Baeri, S.U. Campisano, G. Foti and E. Rimini, J. Appl. Phys. 50(2), 788 (1979).

[15] Ferroelectric Memories, J.F. Scott, Springer, 2000. 